
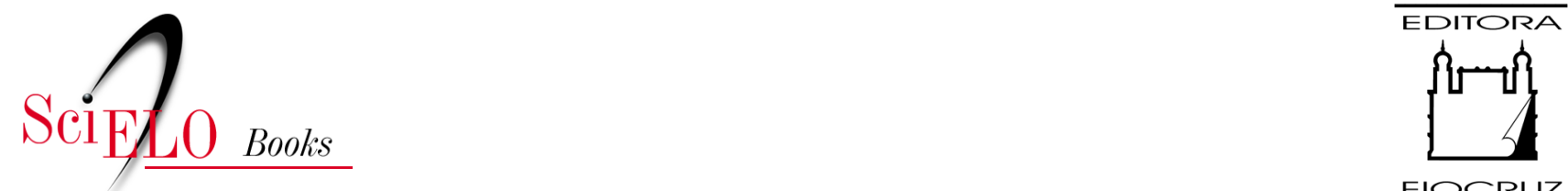

FIOCRUZ

\title{
4. Qual padrão de desenvolvimento? \\ Cenários macroeconômicos a longo prazo
}

\author{
Salvador Werneck Vianna \\ Maria Lucia Werneck Vianna
}

\section{SciELO Books / SciELO Livros / SciELO Libros}

VIANNA, S.W., and VIANNA, M.L.W. Qual padrão de desenvolvimento? Cenários macroeconômicos a longo prazo. In: GADELHA, P., NORONHA, J.C., DAIN, S., and PEREIRA, T.R., eds. Brasil Saúde Amanhã: população, economia e gestão [online]. Rio de Janeiro: Editora FIOCRUZ, 2016, pp. 119-135. ISBN: 978-65-5708-093-1.

https://doi.org/10.7476/9786557080931.0006.

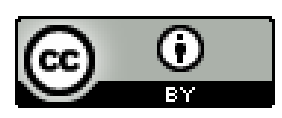

All the contents of this work, except where otherwise noted, is licensed under a Creative Commons Attribution $\underline{4.0 \text { International license. }}$

Todo o conteúdo deste trabalho, exceto quando houver ressalva, é publicado sob a licença $\underline{\text { Creative Commons }}$ Atribição 4.0.

Todo el contenido de esta obra, excepto donde se indique lo contrario, está bajo licencia de la licencia $\underline{\text { Creative }}$ Commons Reconocimento 4.0. 


\title{
QUAL PADRÃO DE DESENVOLVIMENTO? CENÁRIOS MACROECONÔMICOS A LONGO PRAZO'
}

\author{
Salvador Werneck Vianna \\ Maria Lucia Werneck Vianna ${ }^{2}$
}

De acordo com dados da Secretaria de Ciência, Tecnologia e Insumos Estratégicos do Ministério da Saúde, a cadeia produtiva da saúde movimenta um volume de recursos superior a $6 \%$ do Produto Interno Bruto (PIB), emprega diretamente, com trabalhos qualificados formais, parcela expressiva da força de trabalho brasileira e é a área de maior expressão no país em investimentos públicos com pesquisa e desenvolvimento (MS \& Opas, 2015). Em termos de empregos diretos e indiretos, em toda a cadeia produtiva, o conjunto dessas atividades representa cerca de 7,5 milhões de trabalhadores inseridos, predominantemente, em atividades intensivas em conhecimento (MS, 2007). ${ }^{3}$

A saúde, portanto, pode ser considerada em uma dupla perspectiva: numa dimensão, vem a se constituir vetor absolutamente central do sistema de proteção social brasileiro; noutra, permeia toda a cadeia produtiva. Não só as condições macro e microeconômicas da sociedade influenciam a configuração do setor Saúde, como também as vicissitudes deste têm impacto sobre apolítica macroeconômica e sobre o comportamento dos agentes.

É uma relação mútua. Quanto mais se avançar na qualificação e consolidação de instrumentos de política que aprimorem a governança macroeconômica, ${ }^{4}$ maior será a capacidade do Estado

\footnotetext{
${ }^{1}$ Este capítulo foi resultado de um estudo encomendado pela Fundação Oswaldo Cruz (Fiocruz) no âmbito da iniciativa Brasil Saúde Amanhã, cuja conclusão se deu no primeiro semestre de 2014.

Ao ser publicado somente agora, segundo semestre de 2016, apresenta-se o óbvio (e gigante) problema da não inclusão dos anos de 2014 e 2015. Nesse período, como notório, houve uma combinação cataclísmica de crises econômica e política, com resultados dramáticos que incluem uma recessão profunda e prolongada e a deposição de Dilma Roussef da Presidência da República, cujos desdobramentos ainda estão em pleno curso ao escrevemos esta nota (maio de 2016). A análise aqui desenvolvida refere-se ao período de 2003 a 2013 e, portanto, não abarca esse período recente. Cabe destacar que, se isso implica, por um lado, a necessidade de um cuidado ainda maior na avaliação e análise dos cenários de longo prazo construídos na seção final do capítulo, por outro, confirma e corrobora integralmente os argumentos apresentados logo antes da descrição dos cenários, quando ressaltamos a incerteza, em sentido keynesiano, que permeia de modo inexorável o funcionamento dos sistemas econômicos. E que torna, por conseguinte, particularmente difícil, para dizer o mínimo, todo e qualquer exercício de previsão.

2 Agradecemos a Caroline Teixeira Jorge e Camila Ferraz pelo excelente trabalho de assistência de pesquisa.

${ }^{3} \mathrm{O}$ documento da referida secretaria não explicita a fonte dessa informação. As Contas Nacionais do IBGE reportam um total de ocupações nos setores saúde pública, saúde mercantil e farmacêutico que não ultrapassa 3,5 milhões em 2009, último dado disponível. Possíveis exageros à parte, trata-se sem dúvida de uma ordem de grandeza bastante expressiva.

${ }^{4}$ Aqui entendida como o conjunto de ações na gestão do juro, do crédito, da dívida pública e do câmbio, e desenvolvidas com o objetivo de promover o crescimento do emprego e da renda, sem gerar desequilíbrios inflacionários e/ ou de balanço de pagamentos de caráter permanente. Para maiores detalhes, ver Ipea (2010).
} 
de prover, por meio de sistemas como o Sistema Único de Saúde (SUS), bens e serviços de forma mais satisfatória para a população. ${ }^{5} \mathrm{E}$ a convergência para um quadro macroeconômico favorável é condição importante, embora longe de suficiente, para a adoção de reformas que tornem o Estado mais eficiente, dotado de um setor público capaz de arrecadar recursos junto à sociedade da forma mais eficaz, justa e progressiva possível, e de fazer uso - também o mais eficaz, justo e progressivo - desses recursos. É necessário estar apto a planejar e se articular com o setor privado a fim de promover o crescimento da economia de maneira equilibrada e estável - tanto do ponto de vista monetário e financeiro quanto de seu setor externo.

O objetivo deste capítulo é traçar um panorama macroeconômico e da saúde (financiamento, gastos, inovação) no Brasil, de modo a subsidiar a elaboração de cenários prospectivos tanto para a macroeconomia quanto para o setor Saúde no país.

Este estudo dá sequência a um trabalho anterior (Teixeira \& Werneck Vianna, 2013), em que se procurou contribuir para a discussão das condições que podem vir a permear o sistema de saúde brasileiro na quarta década do século XXI.

O objetivo principal constituiu-se, portanto, no desenho da configuração básica de uma moldura descritiva do desempenho das variáveis macroeconômicas, de modo a permitir a visualização das alternativas para o sistema nacional de saúde, em termos de limites e possibilidades que condicionariam tanto seu desenvolvimento quanto a elaboração de políticas públicas para o setor.

Para a consecução de tal objetivo, seguiram-se os seguintes passos:

1) resumo do quadro macroeconômico atual e dos principais pontos de vista presentes no debate sobre a economia brasileira;

2) discussão sobre conceitos e métodos utilizados em estudos prospectivos, bem como sobre limites ao uso de cenários para previsão do quadro macroeconômico;

3) levantamento bibliográfico e resenha dos principais trabalhos prospectivos recentes;

4) definição das variáveis a serem utilizadas na construção dos cenários;

5) breve descrição dos cenários alternativos no horizonte de vinte anos.

Neste capítulo, as variáveis apresentadas e analisadas anteriormente foram revistas e atualizadas. Além disso, procurou-se incluir novas variáveis (de particular interesse as referentes a consumo, investimento, inovação, infraestrutura e economia externa).

A primeira seção consiste numa análise retrospectiva, explorando alguns contornos da política macroeconômica na última década, assim como seus condicionantes internos e externos. A segunda seção apresenta um conjunto de dados abarcando aspectos micro e macroeconômicos do setor Saúde: financiamento, gastos, papel estratégico da saúde na inovação. A terceira discute e analisa a construção dos cenários prospectivos a longo prazo, assim definidos como o período de duas décadas à frente.

\footnotetext{
${ }^{5}$ Por sistema entende-se a política pública que engloba os diferentes níveis de governo, com metas, ações e mecanismos de financiamento estabelecidos e consolidados. Uma questão que vem ganhando importância é sobre como integrar as ações e políticas em áreas como educação e segurança pública, tornando-as também sistemas (únicos ou não).
} 


\section{Panorama Macroeconômico: 2003-2013}

Embora não se intencione estabelecer comparações entre diferentes governos, há uma considerável mudança de patamar da economia brasileira em diversos aspectos a partir de 2003, quando se inicia um novo governo federal. Ao final dos oito anos do governo Cardoso (1995-2002), a inflação média, medida pelo Índice Nacional de Preços ao Consumidor Amplo (IPCA), havia sido de 9,1\% ao ano, e o crescimento real do PIB foi, em média, da ordem de 2,3\% ao ano. Em 2010, findos os dois períodos de governo Lula, a inflação anual média ficou em 5,77\% (dentro, portanto, da meta definida pelo Conselho Monetário Nacional), e o crescimento do PIB, também em termos médios anuais, em 4,03\%. Além disso, houve melhoras na distribuição de renda: o índice de Gini recuou de 0,59, em 2002, para 0,53 em 2010.

Tal mudança de patamar, que de resto se verifica também em outras variáveis relevantes (relativas ao setor externo e ao mercado de trabalho, por exemplo), não ocorreu pura e simplesmente pela adoção de políticas, por assim dizer, mais virtuosas por parte do governo do PT, vis-à-vis o governo do PSDB. Na verdade, foi a interação entre grandes mudanças nas condições externas com as quais a economia brasileira se defrontava desde 2003 e pequenas mudanças na orientação da política econômica doméstica que explica, em grande parte, o avanço no controle inflacionário, a recuperação das taxas de crescimento do PIB e a melhora na distribuição de renda registradas na segunda metade da década passada.

No cenário externo, a grande mudança observada foi a intensa aceleração das taxas de crescimento econômico das economias ditas "emergentes", com destaque para a China (Tabela 1). A sustentação do ritmo de crescimento chinês, que naquele momento já vinha há quase duas décadas a taxas anuais de dois dígitos, propiciou uma notável elevação dos preços das commodities, incluindo alimentos, o que representou um enorme impulso para as exportações brasileiras desses produtos.

Tabela 1 - Taxas reais de crescimento econômico comparadas (\% a. a.). Brasil e países selecionados 2005-2013

\begin{tabular}{|c|c|c|c|c|c|c|c|c|c|c|}
\hline Crescimento do PIB & $\begin{array}{c}\text { Média } \\
1995-2004\end{array}$ & 2005 & 2006 & 2007 & 2008 & 2009 & 2010 & 2011 & 2012 & 2013 \\
\hline Economias avançadas & 2,8 & 2,8 & 3,0 & 2,7 & 0,1 & $-3,4$ & 3,0 & 1,7 & 1,5 & 1,2 \\
\hline Economias emergentes & 4,9 & 7,3 & 8,3 & 8,7 & 5,8 & 3,1 & 7,5 & 6,2 & 4,9 & 4,5 \\
\hline China & 9,2 & 11,3 & 12,7 & 14,2 & 9,6 & 9,2 & 10,4 & 9,3 & 7,7 & 7,6 \\
\hline Índia & 6,2 & 9,3 & 9,3 & 9,8 & 3,9 & 8,5 & 10,5 & 6,3 & 3,2 & 3,8 \\
\hline Brasil & 2,5 & 3,2 & 4,0 & 6,1 & 5,2 & $-0,3$ & 7,5 & 2,7 & 0,9 & 3,0 \\
\hline México & 2,4 & 3,2 & 5,0 & 3,1 & 1,2 & $-4,5$ & 5,1 & 4,0 & 3,6 & 1,2 \\
\hline
\end{tabular}

Fonte: elaboração dos autores com base em dados do IMF, 2014. 
Adicionalmente, o setor exportador brasileiro - notadamente o vinculado às commodities metálicas - foi beneficiado, num primeiro momento, por uma posição excepcionalmente favorável da taxa de câmbio, ocasionada pela intensa desvalorização do real desencadeada pelas incertezas e temores dos mercados financeiros diante da transição de governos em fins de 2002 (Gráfico 1).

Gráfico 1 - Taxa nominal de câmbio R\$/US\$ - médias anuais - 2002-2013

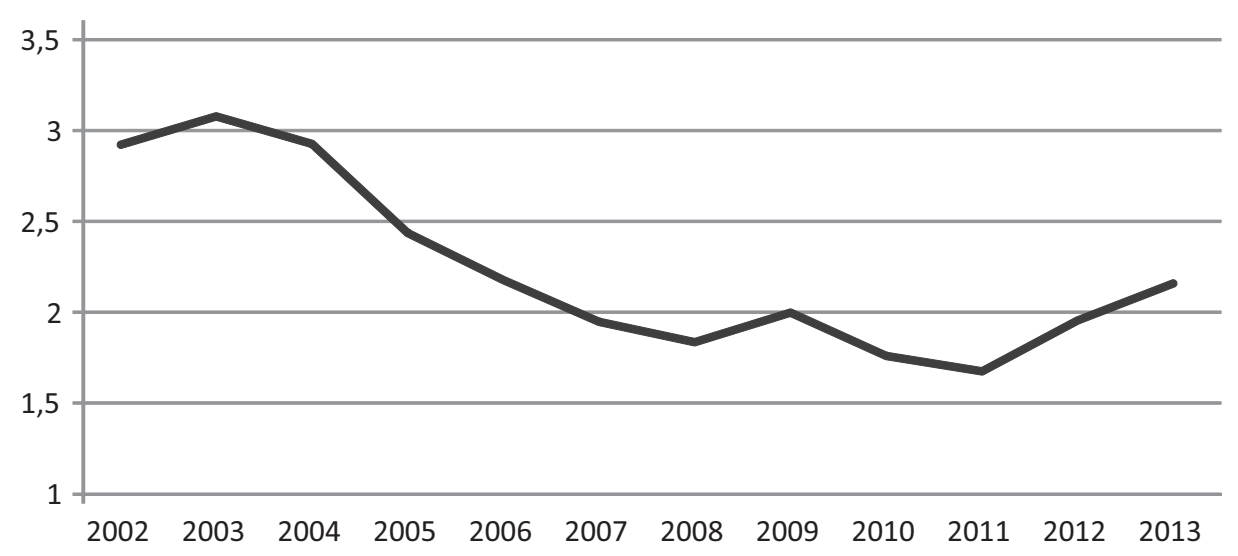

Fonte: elaboração dos autores com base em dados do Banco Central do Brasil - Sistema Gerador de Séries Temporais (BCB - SGS).

Esse duplo impulso, dado pela conjugação de uma taxa de câmbio desvalorizada com um cenário de termos de troca favoráveis, foi bem aproveitado pelo setor exportador de bens primários, o que se traduziu numa efetiva redução das vulnerabilidades externas da economia brasileira, que marcaram a década de 1990. A substantiva elevação do nível das reservas internacionais constitui em si um dado revelador, embora não o único, dessa nova realidade, que de resto permitiu à economia brasileira atravessar, sem maiores sobressaltos, os piores anos da severa crise internacional desencadeada nas economias avançadas a partir de 2007.

Do ponto de vista da gestão da política macroeconômica, os primeiros anos do governo Lula foram marcados pela manutenção, e em alguns aspectos até aprofundamento, do arcabouço do governo anterior. O assim chamado "tripé" - regime monetário de metas de inflação, câmbio flutuante e disciplina fiscal - foi mantido, com algumas nuances, como, por exemplo, o estabelecimento de uma meta maior de superávit primário. A política econômica reafirmava, assim, o compromisso prioritário com a estabilidade de preços, em detrimento de objetivos relacionados ao crescimento da renda e do emprego. A política monetária, nesse sentido, constituía-se no instrumento-chave para esse compromisso, cabendo às políticas cambial e fiscal funções meramente coadjuvantes.

A manutenção de taxas básicas de juros (nominais e reais) em patamares elevados tem sido uma característica distintiva da política econômica brasileira, ainda que a tendência, na última década, tenha sido de (relativa) flexibilização. Além de atuar diretamente na contenção da demanda agregada, reduzindo o nível de atividade, a política de juros altos atua também como fator de atração de capitais externos de curto prazo. Esses capitais, ao entrarem na economia, ampliam a oferta de divisas 
e consequentemente contribuem para a apreciação da taxa de câmbio, o que por sua vez torna mais baratos os bens importados. A valorização do real, portanto, é um subproduto desejado da política monetária (ainda que isto não seja declarado pelo Banco Central do Brasil - BCB), na medida em que constitui poderoso instrumento auxiliar no controle inflacionário.

Não obstante, é inequívoca uma tentativa de mudança de orientação da política monetária a partir de 2010, quando se inicia o governo Dilma na Presidência da República. Os juros reais, que ficaram em média na casa de $8,5 \%$ no período 2003-2010, despencaram para 3,1\% no triênio 20112013, movimento esse cuja maior explicação deriva da redução significativa da taxa básica nominal (Selic). Em que pese uma recuperação, ainda que modesta, das taxas de investimento, é fato que o crescimento econômico tem se mantido em ritmo lento (Gráfico 2). ${ }^{6}$

Gráfico 2 - PIB-Brasil - variação real anual (\%) - 2002-2012

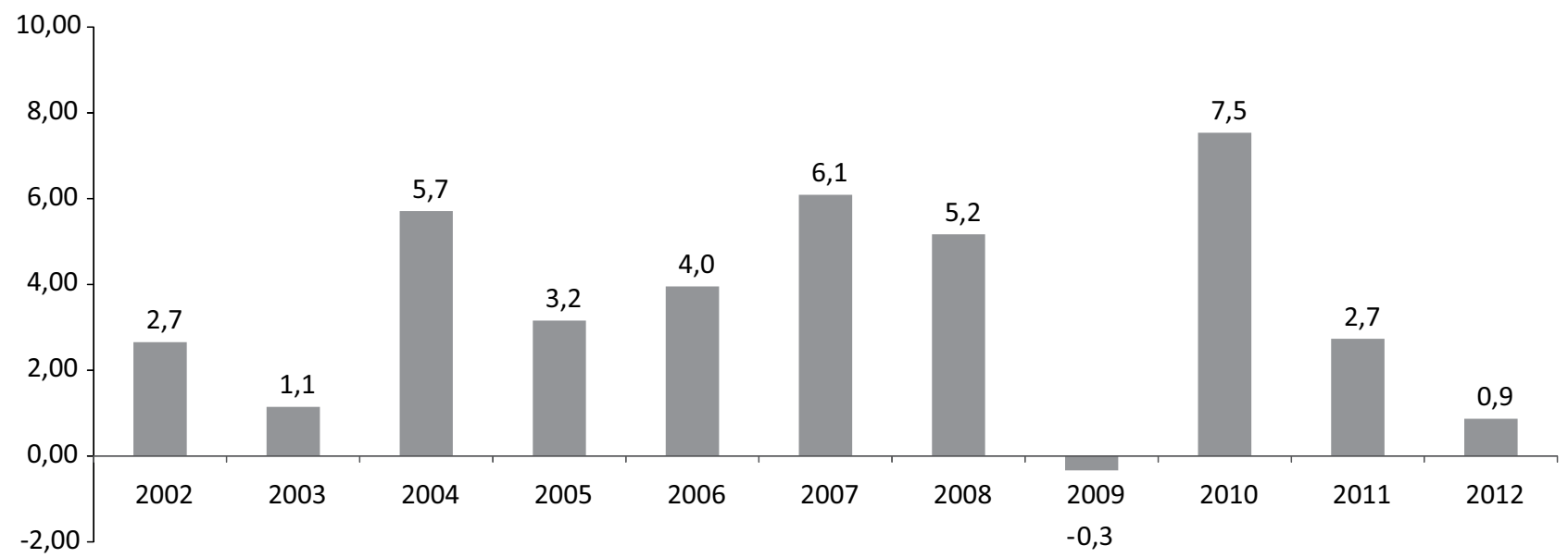

Fonte: elaboração dos autores com base em dados do Sistema de Contas Nacionais do IBGE.

Resta pouca dúvida, no entanto, de que o governo Lula soube, na medida do possível, aproveitar o vigoroso impulso dado à economia pelo setor externo (as "grandes mudanças" aludidas anteriormente) para, por meio de intervenções pontuais (as "pequenas mudanças"), lograr dinâmicas positivas nos níveis de emprego e de renda.

Por mais positivas que tenham sido tais dinâmicas, elas foram insuficientes para alterar estruturalmente o mercado de trabalho. Prevalecem ainda empregos de baixa remuneração e alta rotatividade, o que restringe o crescimento da produtividade e, consequentemente, a expansão da economia a taxas maiores e sustentadas. Indícios claros nesse sentido são os incrementos modestos do rendimento médio dos trabalhadores e da parcela no PIB da renda do trabalho (gráficos 3 e 4).

\footnotetext{
${ }^{6}$ Esse quadro por certo reflete ainda os efeitos da crise internacional e a consequente redução do ritmo de crescimento da economia global.
} 
Gráfico 3 - Rendimento médio real efetivo das pessoas ocupadas nas regiões metropolitanas $(\mathrm{R} \$)-2003-2013$

$$
2.500,0
$$

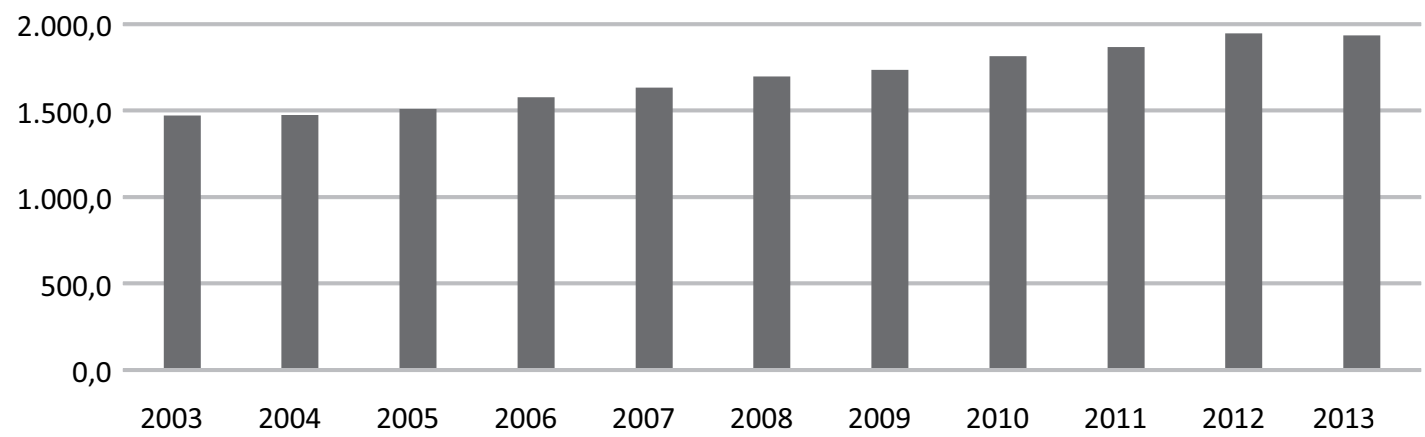

Fonte: elaboração dos autores com base em dados da Pesquisa Mensal de Emprego do IBGE.

Gráfico 4 - Rendimentos do trabalho (\% do PIB) - 2003-2009

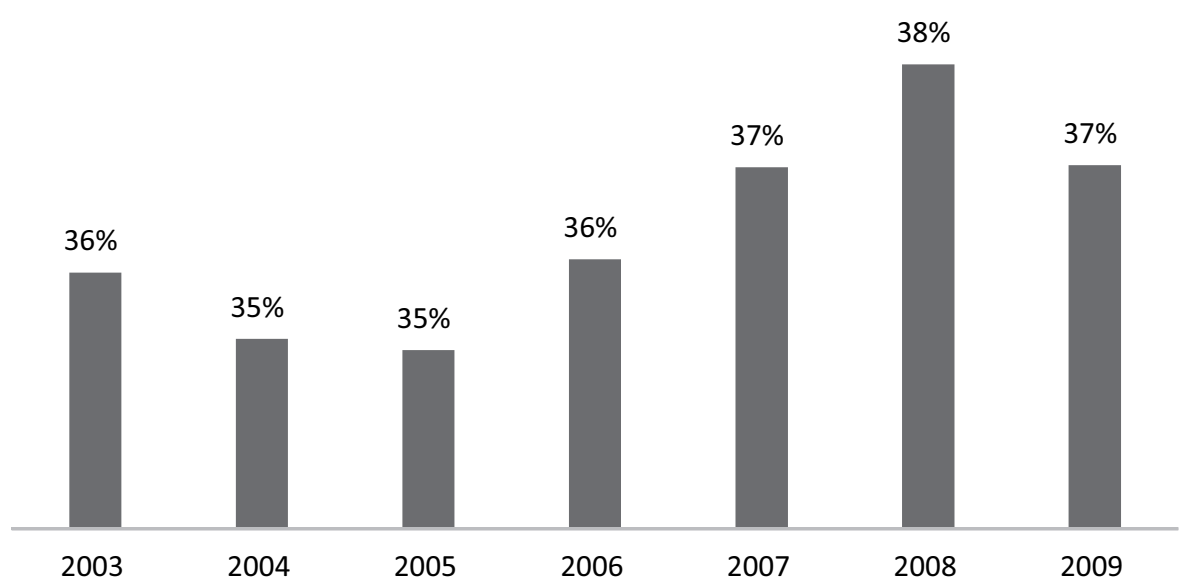

Fonte: elaboração dos autores com base em dados da Pesquisa Mensal de Emprego do IBGE.

Há que se destacar, ainda, a expressiva expansão do crédito oferecido pelo setor financeiro (público e privado), assim como do ritmo de inclusão de parcelas crescentes da população ao sistema bancário (gráficos 5 e 6). A combinação destes fenômenos com o aumento do emprego forjou o regime de crescimento do período 2003-2010, baseado principalmente no consumo das famílias. 
Gráfico 5 - Crédito do sistema financeiro (\% do PIB) - 2003-2012

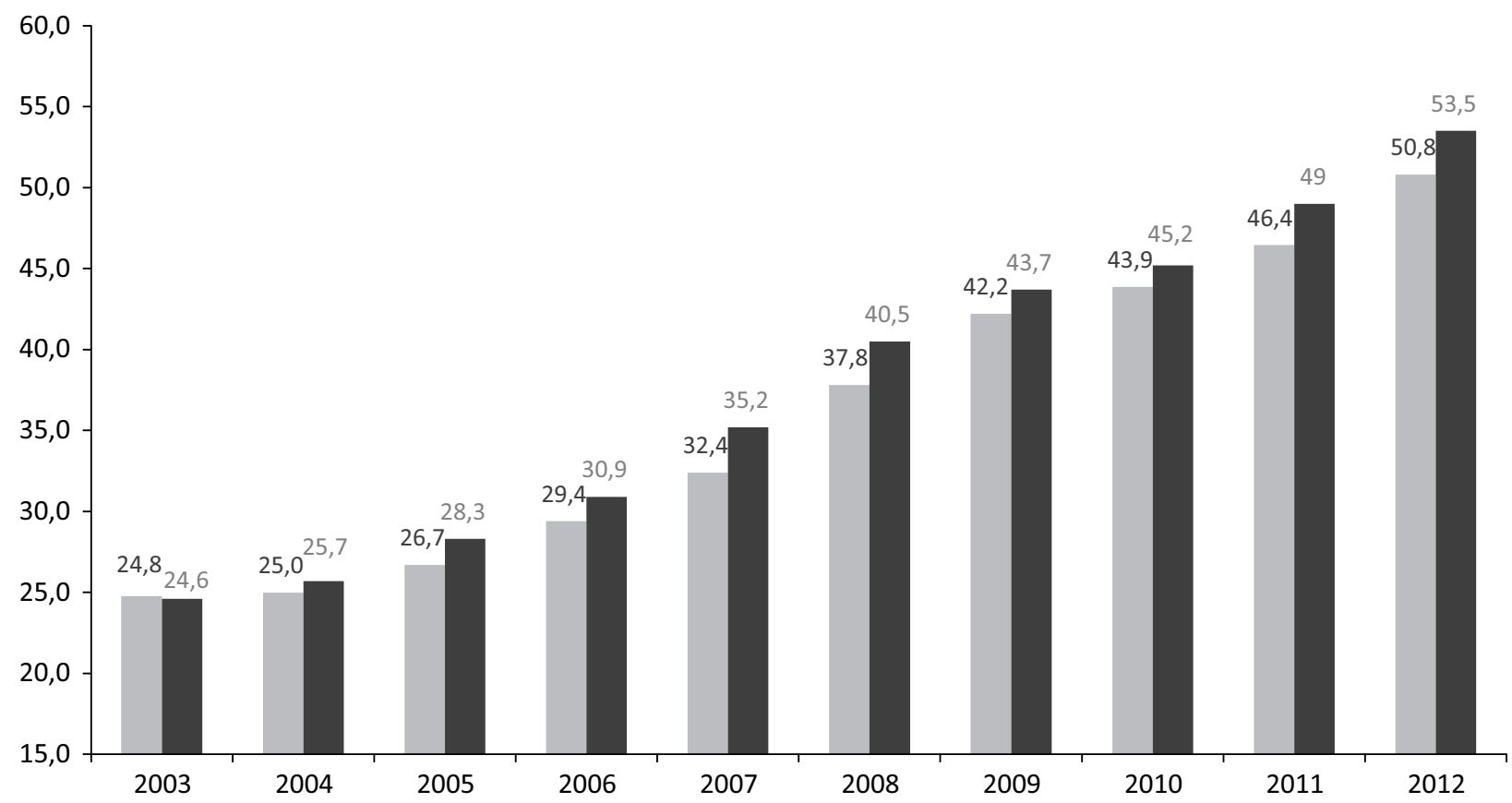

Crédito do sistema financeiro/PIB - \% - média do ano

Crédito do sistema financeiro/PIB - \% - dezembro do ano

Fonte: elaboração dos autores com base em dados do Banco Central do Brasil - Sistema Gerador de Séries Temporais (BCB - SGS).

Gráfico 6 - Inclusão financeira* (\% população) - 2006-2012

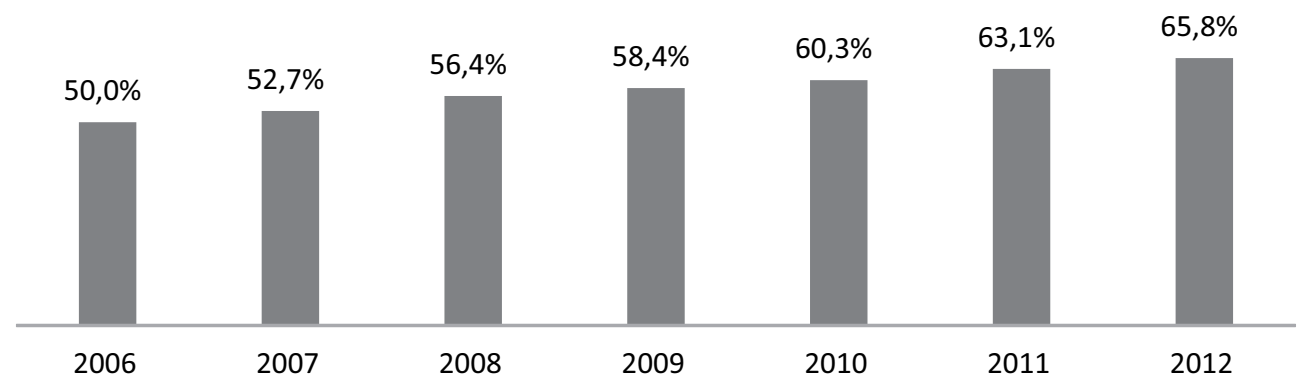

\footnotetext{
* Percentual da população residente com relacionamentos bancários, incluindo conta corrente, conta poupança ou outro relacionamento bancário.

Fonte: elaboração dos autores com base em dados do Cadastro de Clientes do Sistema Financeiro Nacional do Banco Central do Brasil (CPFs ativos ao final de cada ano) e da Diretoria de Pesquisas, Coordenação de População e Indicadores Sociais (população residente).
} 
A interação dessas políticas, associada ainda a outros fatores, como a recuperação do valor real do salário mínimo e a expansão de programas distributivos como o Bolsa Família, propiciou a melhora, ainda que modesta, de importantes indicadores sociais. Houve quedas nos segmentos pobres e extremamente pobres da população, e melhora na distribuição de renda medida pelo índice de Gini (Tabela 2).

Tabela 2 - Parcelas da população por estratos de renda. Brasil - 2003 e 2011

\begin{tabular}{|l|c|c|c|}
\hline \multirow{2}{*}{\multicolumn{1}{c|}{ Estratos }} & \multicolumn{3}{|c|}{ Famílias } \\
\cline { 2 - 4 } & $2003(\%)$ & $2011(\%)$ & Variação (p. p.) \\
\hline Extremamente pobres & 5,5 & 2,6 & $-2,9$ \\
\hline Pobres & 12 & 4,4 & $-7,7$ \\
\hline Vulneráveis & 50,5 & 44,8 & $-5,6$ \\
\hline Não pobres & 32 & 48,2 & 16,2 \\
\hline Total & 100 & 100 & - \\
\hline Coeficiente de Gini & 0,576 & 0,523 & $-9,2$ \\
\hline
\end{tabular}

Nota: os quatro estratos foram definidos pelos autores com base na renda domiciliar per capita: extremamente pobres (famílias com renda inferior a $\mathrm{R} \$ 70,00$, em reais de 2011); pobres (renda maior ou igual a $\mathrm{R} \$ 70,00$ e inferior a $R \$ 140,00$ ); vulneráveis (renda maior ou igual a $R \$ 140,00$ e menor que $R \$ 560,00$ ); e não pobres (renda maior ou igual a $\mathrm{R} \$ 560,00)$. A linha de vulnerabilidade foi estabelecida como quatro vezes o valor da linha de pobreza.

Fonte: Souza \& Osório, 2013: 146.

\section{Aspectos Microeconômicos: financiamento, gastos e papel estratégico do setor Saúde na inovação}

O desenho do sistema de proteção social contemplado na Constituição Federal de 1988 baseia-se num modelo contributivo para as aposentadorias, mas com regime especial para os trabalhadores rurais, universal na saúde e sujeito a controles de insuficiência de renda no caso das transferências assistenciais (Benefício da Prestação Continuada da Lei Orgânica da Assistência Social - BPC/Loas). Já o financiamento da seguridade social foi estruturado com base em contribuições diretas ao sistema previdenciário (contribuições dos empregados e empregadores ao Instituto Nacional do Seguro Social - INSS - e contribuições ao regime de previdência do setor público), impostos e taxas vinculados à seguridade social - Contribuição para Financiamento da Seguridade Social (Cofins), Contribuição Social sobre o Lucro Líquido (CSLL), Programa de Integração Social/Programa de Formação do Patrimônio do Servidor Público (PIS/Pasep) e Fundo de Pobreza - e em tributos não previamente vinculados à seguridade social.

A diversificação das fontes de arrecadação representou uma conquista de grande importância, na medida em que reduziu a sujeição do volume de receitas às oscilações do ciclo econômico, ${ }^{7}$ e

\footnotetext{
7 Segundo Gentil e Santos (2009: 153), "a diversificação das fontes de arrecadação do sistema de seguridade social, com a inclusão de contribuições sociais incidentes sobre o lucro e o faturamento, foi uma conquista de grande importância, porque a previdência financiada unicamente pela folha de salários entrou em crise nos anos 1980, quando a economia brasileira enfrentou recessão e o emprego desabou".
} 
simultaneamente ampliou os recursos ao financiamento da seguridade social. A construção dessa compatibilidade entre a política econômica e o aumento dos recursos disponíveis para a seguridade social foi uma das grandes responsáveis pela melhora consistente da distribuição de renda nos últimos vinte anos, possibilitando a viabilização do aumento das transferências públicas para as camadas mais pobres da população e o pagamento do serviço da dívida pública (Gentil \& Santos, 2009).

Apesar dos avanços do Sistema Único de Saúde, o aumento dos gastos privados é uma questão real, que vem ganhando importância crescente, uma vez que se torna um item de despesa extremamente oneroso (e regressivo) no orçamento das famílias (Tabela 3).

Tabela 3 - Gastos em saúde, públicos e privados, no Brasil e no mundo - 2001 e 2011

\begin{tabular}{|l|r|r|r|r|}
\hline & \multicolumn{3}{|c|}{ Brasil } & \multicolumn{2}{|c|}{ Mundo } \\
\hline & 2001 & 2011 & 2001 & 2011 \\
\hline Gastos em saúde/Gastos totais (\%) & 4,7 & 8,7 & 12,4 & 15,3 \\
\hline Planos privados de saúde/Gastos privados em saúde (\%) & 35,0 & 40,4 & 39,6 & 37,2 \\
\hline Gasto governamental em saúde per capita (US\$) & 96,3 & 512,6 & 285,2 & 614,8 \\
\hline
\end{tabular}

Nota: valores expressos em dólares americanos com base em taxas médias de câmbio de cada ano.

Fonte: elaboração dos autores com base em dados do Global Health Observatory Data Repository da Organização Mundial da Saúde.

Em relação às despesas familiares, os dados da Pesquisa de Orçamentos Familiares 2008-2009 (IBGE, 2012) mostram que:

1) $40 \%$ das famílias com menor rendimento destinam $74,2 \%$ desses gastos para medicamentos, enquanto entre os $10 \%$ com maiores rendas esse percentual é de 33,6\%;

2) O acesso aos planos de saúde costuma ser limitado, concorrendo para isso a alta proporção de despesas com alimentação, habitação e transporte no orçamento doméstico das famílias. As despesas com planos de saúde correspondem a $7 \%$ dos gastos dos $40 \%$ mais pobres, contra $42,3 \%$ dos $10 \%$ mais ricos.

A expansão dos gastos globais se reflete também no surgimento de desequilíbrios no setor industrial ligado ao complexo da saúde. Os gargalos produtivos e a falta de investimentos em áreas de alto conteúdo tecnológico, como a produção de farmoquímicos, impactam fortemente a balança comercial com o aumento crescente do conteúdo importado.

O aumento das importações nesses setores evidencia tais gargalos. Segundo Carneiro (2010), o setor Equipamentos Médicos e de Hospital, Automação Industrial e Precisão teve um aumento do coeficiente de penetração de importações de 32,7 pontos percentuais (p. p.) para 35,1 p. p. entre 1996 e 2008. Isso mostra que "a indústria brasileira está substituindo a produção doméstica de insumos por importados de maneira rápida" (Serrano \& Summa, 2011: 29), o que reforça o desafio ainda existente em termos de política industrial para o país. 


\section{Cenários Prospectivos}

As técnicas de construção de cenários usualmente aplicadas em estudos prospectivos percorrem uma trajetória em que os cenários aparecem como resultado. As metodologias podem variar, conforme a orientação e a percepção teórica do autor, mas é sempre de uma dada combinação de fatores que resulta a construção do cenário.

As limitações dessa técnica são evidentes e já foram destacadas por muitos autores. Simonsen (1972), quatro décadas atrás, já mostrava o erro em que incorrem os economistas quando formulam projeções para o comportamento da economia a longo prazo, baseadas em evidências tópicas a curto prazo. Rigorosamente falando, e considerando o que os economistas chamam de curto e longo prazo, tal como os concebeu Alfred Marshall (1985), em seu Principles of Economics, não se pode cometer o equívoco de imaginar que uma tendência a longo prazo seja uma sequência de tendências a curto prazo; nem que, portanto, conhecendo-se as tendências que configuram uma dada conjuntura, seja possível estabelecer uma trajetória para o futuro a longo prazo.

O futuro é rigorosamente marcado pela incerteza - que não pode ser definida em termos probabilísticos. E essa incerteza é vivida pelos agentes econômicos de forma não necessariamente convergente e coordenada. Ao contrário, os agentes econômicos formam suas expectativas de modo diferenciado e agem de acordo com essas expectativas. Só que suas decisões (ou indecisões) acarretam custos, e, caso se frustrem, não haverá como corrigi-las em curto prazo. O comportamento dos agentes econômicos não se coaduna, portanto, com modelos de expectativas adaptativas, nem, muito menos, com os de expectativas racionais. A incerteza, de acordo com Keynes, é uma força endógena no funcionamento do sistema capitalista, e é ela a responsável pela instabilidade própria à evolução da economia.

Se observarmos a situação por que passa a economia mundial hoje - e, dentro dela, o estado em que se encontram os países centrais -, pode-se facilmente concluir que os fatores de instabilidade são múltiplos, variados e de difícil previsibilidade. Mais do que isso, é difícil prever o impacto que cada um desses fatores terá nas economias da periferia, mesmo em um país com sólidos fundamentos macroeconômicos como o Brasil.

Exatamente por isso - e porque estudos prospectivos e construção de cenários devem ser utilizados como ferramentas para o planejamento e não como exercício de futurologia - foi adotado aqui o caminho inverso. O ponto de partida é a definição dos cenários - ou, mais precisamente, do cenário otimista - com o dimensionamento das variáveis relevantes; só depois é que foi estabelecida a trajetória que a economia brasileira deve percorrer para alcançá-los, em termos de decisões de política econômica e de fatos estruturais impactantes. Alternativamente ao cenário otimista, foram interpostos obstáculos (inclusive pela não adoção de políticas adequadas) que impediriam a economia brasileira de atingir o cenário mais favorável.

A literatura frisa a necessidade de mecanismos de acompanhamento e monitoramento, como instrumentos indispensáveis para o bom uso das técnicas de estudos prospectivos e construção de cenários (Teixeira \& Werneck Vianna, 2013). Dada a metodologia aqui adotada (que parte do cenário para a trajetória), mais importante ainda será o acompanhamento do desempenho das variáveis. Só assim 
poder-se-á garantir que fatos imprevistos, novos desenhos no quadro internacional ou fatores ligados à incerteza e à instabilidade inerentes ao capitalismo serão levados em conta e inseridos na prospecção do futuro. Só assim essas ferramentas tornar-se-ão de fato úteis para o planejamento econômico.

No que concerne às possibilidades de o país ingressar num ciclo longo de crescimento sustentado, isto é, sem gerar pressões sobre a inflação nem sobre o balanço de pagamentos, há um relativo consenso, baseado na evidência empírica brasileira, de que o crescimento continuado a taxas próximas de $5 \%$ ao ano requer uma taxa de investimento (formação bruta de capital em relação ao PIB) em torno de $25 \%$ do PIB. E, em que pese o fato de o investimento agregado no Brasil vir registrando, desde 2004, taxas de crescimento bem superiores às do PIB (à exceção de 2009 e 2012), ainda assim o nível atual do investimento permanece em patamares considerados baixos (pouco superior a 18\% do PIB, em 2012), em relação tanto à média dos países em desenvolvimento, quanto à média histórica do país.

A questão de fundo em relação ao investimento no Brasil remete, em última análise, ao padrão de crescimento que o país vem apresentando nos últimos anos. Assim, a expansão recente do investimento está majoritariamente associada aos setores que mais têm contribuído para o crescimento da economia: agronegócio e extrativismo mineral. Com efeito, os investimentos nos setores intensivos em recursos naturais e em escala respondem por cerca de $80 \%$ do total da formação bruta de capital.

O investimento é a variável-chave de uma economia; inserido numa estratégia adequada, funciona como ponte intertemporal entre diferentes estágios de desenvolvimento, permitindo a superação de gargalos de oferta e a implementação de transformações estruturais. Nesse sentido, o grande desafio para o desenvolvimento brasileiro é a expansão significativa do investimento em três setores estratégicos: infraestrutura urbana e logística, energia e indústria de transformação. É absolutamente imprescindível a liderança do Estado nesse processo, em particular nos dois primeiros setores.

\section{Cenário otimista e possível}

- O PIB crescerá a uma taxa entre 3 e 4\% a. a. - intervalo em que situa a média verificada no período de dez anos encerrado em 2013-3,5\%. Isso implica um crescimento vigoroso do nível de atividade econômica (vis-à-vis a atual conjuntura) e, portanto, um enfrentamento virtuoso dos obstáculos e restrições decorrentes da crise internacional, bem como a introdução de correções na implementação dos instrumentos de política econômica.

- O PIB alcançará em 2033 o expressivo valor de R\$ 10.477 bilhões, a preços constantes de 2013.

- A renda per capita chegará a $\mathrm{R} \$ 46.379$, a preços constantes de 2013, com uma população pouco superior a 225 milhões de habitantes. Esse valor corresponde (a preços constantes de 2013, em dólares e em reais) a pouco maisde 20 mil dólares anuais e poderá significar, para a população brasileira, a possibilidade de desfrutar de níveis de vida significativamente superiores aos de hoje. A condição para que isso ocorra é que a distribuição de renda também melhore, tanto no conceito de distribuição pessoal quanto no de distribuição funcional.

- O coeficiente de Gini, utilizado normalmente para a distribuição pessoal da renda, deverá chegar a 0,40. Com isso, ele estará situado em patamar mais favorável do que em países da 
América Latina, como Argentina $(0,522)$, Venezuela $(0,491)$ e Uruguai $(0,446)$, e próximo aos observados em países de maior desenvolvimento, como França $(0,327)$, Inglaterra $(0,36)$ e Estados Unidos $(0,408)$.

- A participação dos rendimentos do trabalho no PIB - que serve como proxy para a distribuição funcional da renda - poderá chegar a $50 \%$, o que significa um crescimento expressivo, mas possível.

- A hipótese adotada para a projeção do salário mínimo - que é a da continuidade do acordo firmado com os sindicatos - levará o salário mínimo ao valor de R\$1.441,00 em 2033.

- O rendimento médio do pessoal ocupado terá em 2033 um desempenho positivo, apresentando um crescimento superior ao da renda per capita.

- Níveis de emprego e taxas de desemprego apresentarão resultados favoráveis em 2033, com aumento substancial do primeiro - principalmente no segmento de trabalhadores com carteira assinada - e redução significativa do segundo indicador.

- A taxa básica de juros convergirá para a taxa média praticada nos países da Organização para a Cooperação e Desenvolvimento Econômico (OCDE) (1,65\%), o que indica ter havido uma alteração radical nas condições fiscais e financeiras do Estado brasileiro: o serviço da dívida pública terá experimentado uma redução significativa, e as contas públicas apresentarão um resultado primário próximo de zero.

- O Estado, em consequência, terá readquirido sua capacidade de endividamento e de utilização do gasto como instrumento de promoção do crescimento e do emprego.

- A taxa de câmbio terá sofrido pronunciada desvalorização, condizente com as políticas macroeconômicas centradas no crescimento econômico e na promoção do emprego; seu valor oscilará em torno de $\mathrm{R} \$ 2,50$ por dólar.

- O comportamento do balanço comercial é de difícil previsão, não apenas em virtude da instabilidade do comércio mundial em tempos de crise, mas principalmente porque, se o desenvolvimento experimentado pelo país incrementará as exportações (principalmente de manufaturados e serviços de maior valor agregado), ampliará também as importações, principalmente de bens de capital e bens intermediários, indispensáveis à sustentação do crescimento.

- O resultado da conta corrente do balanço de pagamentos apontará para uma situação de maior conforto para a gestão das políticas macroeconômicas.

- A inflação, controlada não apenas pelos instrumentos convencionais de política monetária, mas por políticas adequadas à consolidação das tendências de crescimento da economia, ocupará o centro da meta.

- Aproveitamento das condições favoráveis internacionais para a promoção de crescimento econômico elevado com melhoria dos padrões socioeconômicos do país: ampliação do espaço fiscal para investimentos (ampliação da cobertura e qualidade do sistema público de saúde), melhorias em infraestrutura urbana, maior acesso a bens e serviços públicos de qualidade, salto em educação, amplo investimento em inovação, realização das metas do Plano Brasil Maior. 


\section{Cenário pessimista e plausível}

- O PIB crescerá a uma taxa de 0,56\%, que é exatamente a taxa de crescimento populacional. Isso significa que as vicissitudes do quadro internacional não terão um enfrentamento adequado e que recrudescerá o viés conservador e monetarista da política econômica.

- O valor do PIB no horizonte considerado será de R\$ 5.945 bilhões, a preços de 2013.

- A renda per capita permanecerá a mesma de 2013: $\mathrm{R} \$ 26.316$, o que significa um empobrecimento relativo da população brasileira, e acarretará impactos negativos na distribuição de renda.

- A tendência à melhoria da distribuição pessoal da renda, medida pelo coeficiente de Gini, será, portanto, detida, e esse indicador estabilizará no patamar de 0,60.

- Igual tendência experimentará a distribuição funcional da renda, medida pela participação dos rendimentos do trabalho no PIB, que, se não cair, deverá na melhor hipótese permanecer no mesmo nível de 2013.

- O salário mínimo, nos marcos da hipótese anteriormente mencionada, relativa à continuidade do acordo com os sindicatos, não ultrapassará $\mathrm{R} \$ 810,00$, o que pode ser um fator a alimentar tensões sociais e disputas trabalhistas.

- O rendimento médio do pessoal ocupado tenderá a crescer a uma taxa inferior à da renda por habitante, em decorrência tanto do baixo valor do salário mínimo, que baliza e serve como piso salarial no mercado de trabalho, quanto das pressões oriundas da transição demográfica que se encontrará em fase avançada. Em 2033, no cenário mais provável (o que os demógrafos denominam variante média populacional), a estrutura etária da população brasileira estará fortemente concentrada nas faixas adultas (grupos etários entre 15-19 e 50-54 anos); com o baixo crescimento, não será possível evitar as implicações da dinâmica demográfica em termos de perda de poder de barganha dos trabalhadores nas negociações salariais e de aumento do grau de informalização e de precarização no mercado de trabalho.

- Nível de emprego e taxa de desemprego refletirão as condições negativas do desempenho da economia brasileira, reduzindo-se o primeiro e elevando-se a segunda. A ausência de crescimento do emprego está relacionada com as tendências negativas dos indicadores de distribuição de renda e do rendimento médio do pessoal ocupado.

- A taxa básica de juros permanecerá nos níveis atuais (11\% a. a.), em decorrência da continuidade de políticas conservadoras que priorizam o controle inflacionário e a atração de capitais externos para o fechamento do balanço de pagamentos.

- As contas públicas continuarão a sofrer progressiva deterioração, em virtude tanto do baixo crescimento quanto da permanência das taxas de juros em patamares elevados. Superávits primários crescentes continuarão a ser a meta da política econômica para permitir o pagamento das despesas financeiras relacionadas ao serviço da dívida pública.

- A taxa de câmbio permanecerá sobrevalorizada, mantendo-se em níveis entre $\mathrm{R} \$ 1,80$ e $\mathrm{R} \$ 2,00$ por dólar (a valores de 2013).

- As contas externas (balanço comercial e balanço das transações correntes) não sofrerão grande alteração. 
- A inflação ocupará o centro da meta.

- A restrição ao crescimento econômico diminuirá severamente o (já pequeno) espaço fiscal para investimentos sociais; tenderá a haver piora dos indicadores de inovação (especialização regressiva da estrutura produtiva), da infraestrutura urbana e social e das condições de vida da população, bem como diminuição da cobertura e da qualidade dos serviços públicos de saúde.

\section{Cenário conservador e provável}

- O PIB crescerá a uma taxa inferior à da média dos últimos dez anos - 2,0\% a. a. - mas superior à taxa de crescimento demográfico. O impacto da crise internacional sobre a economia brasileira será significativo e a adoção de instrumentos de política econômica voltados para o crescimento e a promoção do emprego será tímida.

- O PIB registrará, em 2033, o montante de R 7.900 bilhões.

- A renda per capita crescerá, mantendo-se a tendência dos últimos anos, e alcançará o valor de $\mathrm{R} \$ 34.972$.

- A distribuição de renda, em ambos os conceitos, continuará a melhorar: o coeficiente de Gini, tal qual no cenário anterior, estabilizará em 0,60 , e a participação dos rendimentos do trabalho no PIB experimentará moderada melhoria.

- O salário mínimo vigente em 2013 será de $\mathrm{R} \$$ 1.076,00, respeitada a hipótese adotada nos demais cenários.

- O rendimento médio do pessoal ocupado tenderá a acompanhar, em maior ou menor grau, a evolução da renda por habitante. Ainda que menos intensos do que no cenário pessimista, os efeitos da transição demográfica também se farão sentir, e o mercado de trabalho dificilmente será capaz de absorver a população em idade laboral (e particularmente as camadas mais jovens), que constituirá a larga maioria da população total. As pressões daí advindas implicarão também o aumento da informalidade e da precarização nas relações de trabalho.

- O nível de emprego e taxa de desemprego permanecerão nos mesmos patamares em que se encontram na atualidade.

- A taxa básica de juros convergirá para a média das que são praticadas pelos países emergentes, chegando a 4,35\% a. a.; esse nível é consistente com as projeções de crescimento moderado da economia.

- A taxa de câmbio oscilará entre R \$2,00 e R \$2,20 por dólar, o que significa uma leve desvalorização.

- As contas externas (balanço comercial e balanço das transações correntes) não sofrerão grande alteração.

- Política macroeconômica comprometida com o desenvolvimento socioeconômico possibilitará melhoria dos bens e serviços públicos, porém limitada a um crescimento econômico mais moderado com menor espaço fiscal (menor ampliação da cobertura e qualidade do sistema público de saúde). Baixo investimento em inovação, cobertura e qualidade dos bens e serviços públicos comprometidas, gargalos no setor de infraestrutura e mobilidade urbana, impactos na qualidade de vida da população. Crescimento econômico não vem acompanhado de uma mudança estrutural de desenvolvimento (Quadro 1). 
Quadro 1 - Cenários macroeconômicos para 2033

\begin{tabular}{|c|c|c|c|c|}
\hline Variável relevante & Situação atual ${ }^{1}$ & $\begin{array}{l}\text { Cenário otimista e } \\
\text { possível }\end{array}$ & $\begin{array}{l}\text { Cenário pessimista } \\
\text { e plausível }\end{array}$ & $\begin{array}{c}\text { Cenário } \\
\text { conservador e } \\
\text { provável }\end{array}$ \\
\hline PIB & $\mathrm{R} \$ 5.316$ bilhões & $\mathrm{R} \$ 10.477$ bilhões & $\mathrm{R} \$ 5.945$ bilhões & R\$ 7.900 bilhões \\
\hline População & 201.032.714 & & 225.896 .169 & \\
\hline Renda per capita & $\mathrm{R} \$ 26.315$ & $\mathrm{R} \$ 46.379$ & $\mathrm{R} \$ 26.315$ & $\mathrm{R} \$ 34.972$ \\
\hline Taxa de crescimento & $2,3 \%$ a. a. & $3,5 \%$ a. a & $0,56 \%$ a. a. & $2,0 \%$ a. a. \\
\hline Taxa de desemprego & $6,7 \%$ & Cai & Aumenta & $\begin{array}{l}\text { Permanece no } \\
\text { mesmo nível }\end{array}$ \\
\hline Salário mínimo & $\mathrm{R} \$ 724,00$ & $\mathrm{R} \$ 1.441,00$ & $\mathrm{R} \$ 810,00$ & $\mathrm{R} \$ 1.076,00$ \\
\hline $\begin{array}{l}\text { Rendimento médio do pessoal } \\
\text { ocupado }\end{array}$ & $\mathrm{R} \$ 1.527,00$ & $\begin{array}{l}\text { Crescimento } \\
\text { superior ao da renda } \\
\text { per capita }\end{array}$ & $\begin{array}{l}\text { Crescimento inferior } \\
\text { ao da renda per } \\
\text { capita }\end{array}$ & $\begin{array}{l}\text { Crescimento } \\
\text { semelhante ao da } \\
\text { renda per capita }\end{array}$ \\
\hline Índice de Gini & $0,543^{2}$ & 0,40 & 0,60 & 0,60 \\
\hline $\begin{array}{l}\text { Rendimentos do trabalho } \\
\text { (participação no PIB) }\end{array}$ & $34 \% \%^{3}$ & $\begin{array}{l}\text { Melhoria } \\
\text { pronunciada }\end{array}$ & $\begin{array}{l}\text { Permanece no } \\
\text { mesmo nível }\end{array}$ & Melhoria moderada \\
\hline $\begin{array}{l}\text { Resultado primário (governo } \\
\text { central) }\end{array}$ & R\$ 91.300 milhões & $\begin{array}{c}\text { Cai } \\
\text { significativamente }\end{array}$ & Aumenta & $\begin{array}{l}\text { Permanece no } \\
\text { mesmo nível }\end{array}$ \\
\hline Resultado primário (\% PIB) & $1,90 \%$ & $\begin{array}{c}\text { Cai } \\
\text { significativamente }\end{array}$ & Aumenta & Cai moderadamente \\
\hline Serviço da dívida pública & R\$ 248,9 milhões & $\begin{array}{c}\text { Cai } \\
\text { significativamente }\end{array}$ & Aumenta & Cai moderadamente \\
\hline Taxa de juros (Selic) & $11 \%{ }^{4}$ & $1,65 \%$ & $11 \%$ & $4,35 \%$ \\
\hline Taxa de câmbio & $\mathrm{R} \$ 2,16 / \mathrm{US} \$ 1,00$ & $\mathrm{R} \$ 2,50$ & $\mathrm{R} \$ 1,80$ & $\mathrm{R} \$ 2,00$ \\
\hline Saldo do balanço comercial & US $\$ 2,56$ bilhões & Sobe & \multicolumn{2}{|c|}{ Permanece no mesmo nível } \\
\hline Déficit em transações correntes & US $\$ 81,37$ bilhões & Cai & \multicolumn{2}{|c|}{ Permanece no mesmo nível } \\
\hline Inflação (IPCA) & $5,91 \%$ & & $4,5 \%$ & \\
\hline
\end{tabular}

${ }^{1}$ Posição em 2013; ${ }^{2}$ posição em 2012; ${ }^{3}$ posição em 2009; ${ }^{4}$ posição em dezembro de 2013.

Fonte: elaboração dos autores com base em dados do IBGE, BCB e Ipeadata.

\section{Considerações Finais}

Procurou-se desenhar os cenários macroeconômicos possíveis, em um horizonte de vinte anos, com vistas a subsidiar um estudo mais amplo, voltado para o planejamento do sistema de saúde brasileiro a médio e longo prazos.

Levando-se em conta as limitações que os estudos prospectivos sempre envolvem, foram apresentadas, desde logo, as dificuldades de ordem analítica e metodológica que necessariamente se colocam para a construção de cenários. 
Tais dificuldades são acrescidas, na atual fase de desenvolvimento do capitalismo brasileiro, pela ocorrência de uma crise internacional, extensa e profunda, cujos desdobramentos ainda não permitem ver o seu fim. Com isso, uma combinação de fatores externos e internos gera instabilidade, que resulta tanto da dinâmica contraditória do desenvolvimento capitalista quanto da incerteza com que os detentores da riqueza, dentro e fora do país (responsáveis, em última instância, pelas decisões de investimento) - incerteza essa que tolda o horizonte com tintas sombrias - olham para o futuro.

Entretanto, como o estudo procurou explorar, o Brasil dispõe de um conjunto de fatores que podem favorecer o enfrentamento da turbulência externa e encontrar caminhos para que o cenário virtuoso se confirme. Tais fatores envolvem elementos de ordem concreta - da transição demográfica à plataforma pré-sal - e de ordem institucional - em especial o sistema de bancos públicos de que o país dispõe. E envolvem também fatores de ordem subjetiva, manifestos na inflexão que a política macroeconômica parece estar experimentando.

Em função de seu impacto macroeconômico sobre a renda, o emprego, o produto nacional e o gasto público, o setor Saúde é inequivocamente estratégico e precisa estar inserido numa política de desenvolvimento. Há amplo espaço para uma agenda de pesquisa que articule a análise macroeconômica às políticas públicas na área da saúde. Em particular, alguma luz precisa ser direcionada aos mecanismos de financiamento ao setor privado que o Estado possui para estimular ações no campo do desenvolvimento industrial e da inovação tecnológica, com alto potencial de impacto positivo sobre a competitividade da indústria nacional e a garantia de oferta de insumos, medicamentos e equipamentos de saúde, democratizando o acesso da população aos bens e serviços necessários à sua sobrevivência saudável e digna.

\section{Referências}

BRASIL. Ministério do Desenvolvimento, Indústria e Comércio Exterior. Balanço executivo do Plano Brasil Maior, 2012. Disponível em: <www.brasilmaior.mdic.gov.br>. Acesso em: 16 abr. 2014.

CARNEIRO, R. Desenvolvimento brasileiro pós-crise financeira: oportunidades e riscos. Texto preparado para o $7^{\circ}$ Fórum de Economia da FGV-SP, 2010. Disponível em: <www.centrocelsofurtado.com.br/arquivos/ image/201108311439510.CARNEIRO1.pdf>. Acesso em: 5 abr. 2014.

GENTIL, D. \& SANTOS, C. A CF/88 e as finanças públicas brasileiras. In: CARDOSO, J. C. (Org.). A Constituição Brasileira de 1988 Revisitada: recuperação histórica e desafios atuais das políticas públicas nas áreas econômica e social. v. 1. Brasília: Ipea, 2009.

INSTITUTO BRASILEIRO DE GEOGRAFIA E ESTATÍSTICA (IBGE). Pesquisa de Orçamentos Familiares 2008-2009: perfil das despesas no Brasil - indicadores selecionados. Rio de Janeiro: IBGE, 2012. Disponível em: <http:// biblioteca.ibge.gov.br/visualizacao/livros/liv61273.pdf>. Acesso em: maio 2014.

INTERNATIONAL MONETARY FUND (IMF). World economic outlook, abr.2014. Disponível em: <www.imf. org >. Acesso em: 15 maio 2014.

INSTITUTO DE PESQUISA ECONÔMICA APLICADA (IPEA). O Brasil na Virada do Milênio: trajetória do crescimento e desafios do desenvolvimento. Brasília: Ipea, 1997.

INSTITUTO DE PESQUISA ECONÔMICA APLICADA (IPEA). Macroeconomia para o Desenvolvimento. Brasília, Rio de Janeiro: Ipea, 2010. (Projeto Perspectivas do Desenvolvimento Brasileiro, livro 4). 
MARSHALL, A. Princípios de Economia. São Paulo: Nova Cultural, 1985.

MINISTÉRIO DA SAÚDE (MS) \& ORGANIZAÇÃO PAN-AMERICANA DA SAÚDE (OPAS). Estratégias para Disseminação da Informação em Economia da Saúde no SUS. Brasília: Ministério da Saúde, 2015. (Série Ecos, Economia da Saúde para Gestão do SUS, eixo 1, v. 2).

SERRANO, F. \& SUMMA, R. Política macroeconômica, crescimento e distribuição de renda na economia brasileira dos anos 2000. Observatório da Economia Global, mar. 2011. (Textos avulsos n. 6).

SIMONSEN, M. H. Brasil 2002. Rio de Janeiro: Apec, 1972.

SOUZA, P. H. G. F. \& OSÓRIO, R. G. O perfil da pobreza no Brasil e suas mudanças entre 2003 e 2011. In: NERI, M. \& CAMPELLO, T. (Orgs.). Programa Bolsa Família: uma década de inclusão e cidadania. Brasília: Ipea, 2013.

TEIXEIRA, A. \& WERNECK VIANNA, S. T. Cenários macroeconômicos no horizonte 2022/2030. In: GADELHA, P.; CARVALHO, J. N. \& PEREIRA, T. R. A Saúde no Brasil em 2030: diretrizes para a prospecção estratégica do sistema de saúde brasileiro. Rio de Janeiro: Fundação Oswaldo Cruz, Ipea, Ministério da Saúde, Secretaria de Assuntos Estratégicos da Presidência da República, 2013.

WORLD HEALTH ORGANIZATION (WHO). Global Health Observatory Data Repository. Disponível em: <apps.who.int/gho/data>. Acesso em: 15 maio 2014. 